\title{
CAESAREAN SECTION AND THE RISK OF POSTPARTAL DEPRESSION: IS THERE A POSSIBLE ROLE OF HEAT SHOCK PROTEINS?
}

\author{
Krunoslav Šporčić ${ }^{1}$, Marko Ćaćić ${ }^{2}$, Krešimir Reiner ${ }^{3}$, Matko Pavlović ${ }^{4}$ \& Slobodan Mihaljević ${ }^{5}$ \\ ${ }^{I}$ Department of Anaesthesiology and Intensive Care Medicine, General Hospital Vinkovci, Vinkovci, Croatia \\ ${ }^{2}$ Department of Cardiology, St. Antonius Hospital Kleve, Kleve, Germany \\ ${ }^{3}$ Department of Anesthesiology and Intensive Care Medicine, Clinic for Obstetrics and Gynecology, \\ University Clinical Hospital Centre Zagreb, Zagreb, Croatia \\ ${ }^{4}$ Department of Psychiatry, General Hospital Bjelovar, Bjelovar, Croatia \\ ${ }^{5}$ Department of Anaesthesiology, Reanimatology and Intensive Care Medicine, \\ University Hospital Centre Zagreb, Zagreb, Croatia
}

received: 8.4.2019;

revised: 7.8.2019;

accepted: 2.9.2019

\section{SUMMARY}

Data on the potential connection between surgical stress during caesarean section and the role of heat shock proteins in development of postpartal depression is lacking in the literature. This is a narrative review with a goal to establish the potential role of heat shock proteins during caesarean section and development of postpartal depression. Systemic hyperinflammatory state, such as the one that occurs during surgery, may trigger protective cell reaction, which is usually called the heat shock response. Results of several researches bring strong evidence of correlation between expression of genes coding for family of heat shock proteins with the onset of depressive symptoms. Also, a recent meta-analysis established caesarean section as a risk factor for development of postpartal depression. It is obvious that heat shock proteins play a certain role in development of psychiatric disorders. However, a role of heat shock proteins in development of postpartal depression remains open for debate. We emphasise the need for a randomised control trial which would enable an answer to the mentioned issue.

Key words: heat shock proteins - caesarean section - postpartal depression

$* * * * *$

\section{INTRODUCTION}

The rate of birth by caesarean section is in it's peak in developed countries, as well as the clinical depression which is the most common mental health condition in the general population. Some data suggest that the rate of delivery by caesarean section increased for almost $50 \%$ over the past two decades. Rate of delivery by caesarean section is around $30 \%$ in most developed countries, which is attributed to maternal factors, such as increasing age and obesity, as well as the evolution in medicine which made caesarean section safer to perform regarding to maternal and fetal morbidity and mortality (Barber et al. 2011, Liston 2003). According to the World Health Organisation, globally more than 300 million people of all ages suffers from depression. Depression is also marked as a leading cause of disability worldwide. World Health Organisation has predicted that by the year 2020, depression will rank second in global disease burdens. Nowadays, worldwide prevalence of depression is estimated to be around 10\% (Grace Y Lim et al. 2018). Some data confirm that more than $10 \%$ of mothers in developed countries are affected by postpartal depression (Lanes et al. 2011). Also, some data from the literature confirm that caesarean section represents a risk factor for developing postpartal depression (Xu et al. 2017). Heat shock proteins are very well recognised factor in inducing stress response during various states, such as the stress response to surgical procedures. Further, some data also suggest the link between heat shock proteins and development of clinical depression. However, there is no data on the potential connection between surgical stress during caesarean section and the possible role of heat shock proteins in development of postpartal depression. This is a narrative review on the role of heat shock proteins in development of postpartal depression after caesarean section.

\section{STRESS RESPONSE TO SURGERY}

Surgical procedures are associated with complex local and systematic inflammatory response, characterised by neurohumoral, immune and metabolic changes. The choice of different anaesthetic techniques may alter the degree of systematic inflammatory response (Türkan et al. 2011, Marana et al. 2003, Malatinsky et al. 1986, Sacredote et al. 2000, Hamberger \& Jarnberg 1983, Kelbel \& Weis 2001, Guisasola et al. 2015). During operative and postoperative period, systemic response of mother and fetus is associated with oxidative stress, which is a result of an increased production of reactive oxygen species, as well as decrease in antioxidant enzymes, accompanied by the release of numerous pro and anti-inflammatory cytokines (Beilin et al. 2003, Mokart et al. 2005). This hyperinflammatory state may trigger protective cell reaction, which is usually called the ,heat shock 
response", and represents a consequence of the cellular response to increased stress levels or high temperature. Within the aforementioned reaction, and proportionally to the intensity of stimulation, there is an increase in concentration of heat shock proteins within different cellular/biological compartments (Marana et al. 2003).

\section{ROLE OF HEAT SHOCK PROTEINS IN PATHOPHYSIOLOGY OF MENTAL DISORDERS}

Recent studies indicate strong connection between systemic inflammatory response followed by oxidative stress with pathophysiology underlying clinically significant episodes of affective disorders. Growing body of evidence suggest that higher expression of genes coding for family of heat shock proteins are in correlation with mood changes and anxiety levels. Nevertheless, the mechanisms of heat shock protein action and subsequent effects on psychic status, as well as its potential role in etiology of mental disorders are still unclear. Results of several researches bring strong evidence of correlation between expression of genes coding for family of heat shock proteins with the onset of depressive symptoms. A longitudinal study of neurotrophic, oxidative, and inflammatory markers in first-onset depression in midlife women confirmed the thesis that inflammation, oxidative stress, and brain-derived neurotrophic factor are all associated with the pathophysiology of major depressive disorder. Study has shown that women suffering from major depressive disorder had higher activity of heat shock protein 70, which is important in cell protection from oxidative stress and direct inhibition of apoptosis, compared to those who did not develop major depressive disorder. Authors have also concluded that development of major depressive disorder in midlife women may be associated with a systemic cascade of pro-oxidative and pro-inflammatory events, including increased levels of heat shock protein 70 and decreased levels of brain-derived neurotrophic factor (Pasquali et al. 2017). Furthermore, heat shock proteins, among other pro-inflammatory proteins, became a new focal point in a pursuit for valid antidepressant efficacy predictors. A study conducted on one hundred and forty two patients suffering from major depressive disorder and treated with antidepressants has shown that genetic variants within the genes coding for family of heat shock protein 70 may affect the action of antidepressants and thus their therapeutic efficacy (Pae et al. 2007). A cross sectional study conducted on patients suffering from ulcerative colitis have shown that those with verified induction of heat shock protein 70 genes in polymorphonuclear cells from the affected areas of colon had significantly higher scores on psychometric scales used for evaluation of anxiety and depression, such as Zung Depression Rating Scale and Spielberg State-Trait Anxiety Inventory (Vlachos et al. 2014). Some authors also suggest that there is a connection between expression of genes coding for family of heat shock protein 70 and levels of brain-derived neurotrophic factor. Researchers have investigated the effects of heat shock protein induction on neural structures in mice, focusing on hippocampal regions. Stressed mice were treated with geranylgeranylacetone, a known heat shock protein inducer. Results have shown evident decrease in hippocampal heat shock protein 105 expression in mice that were affected with stressful stimuli. The same mice have been treated with geranylgeranylacetone and consequently, the expression of heat shock protein 105 was increased. Authors have concluded that there is a correlation between higher heat shock protein 105 expression in hippocampus of a mouse and hippocampal cell proliferation, as well as elevation of brain-derived neurotrophic factor levels. From the clinical aspect, researches have noted improvement of depression-like behavior in mice treated with geranylgeranylacetone (Hashikawa et al. 2017).

Heat shock proteins are a group of proteins and highly conserved molecules that are present in almost all subcellular structures (e.g. nucleus, mitochondria, endoplasmic reticulum and cytoplasm) of all cell types, from prokaryotes to eukaryotes (Robert 2003). Traditionally, heat shock proteins have also been known as molecular chaperones because of their physiological and protective roles in the cells. They facilitate protein folding and maintenance of natural structures, as well as functions of other proteins, when cells are exposed to homeostatic challenges, such as extreme temperature, anoxia, hypoxia, prolonged exposure to heavy metals, drugs, or other chemical agents, that may induce stress or protein denaturation (Liu et al. 2012, Macario et al. 2007).

Human heat shock proteins are categorised under distinct families, based on their functions in the cells, their homologies in the primary structures, and their approximate molecular weight, which is measured in $\mathrm{kDa}$ (Kampinga et al. 2004). They have a dual role, depending on the intracellular or extracellular localisation. Intracellular heat shock proteins have a protective function and enable the cell to survive the deadly conditions (Bruemmer-Smith et al. 2001, Schmitt et al. 2007, Mehlen et al. 1996, Pandey et al. 2000). Extracellular, as well as the heat shock proteins localised on the cell membrane mediate immunological functions and play a key role in the stimulation of the immune system. In humans, the presence of heat shock proteins in serum is associated with the occurrence of stress factors, such as inflammation, bacterial, or viral infection. Although the heat shock proteins are protective and their endogenous increase in response to injury reduces cell damage, they can also lead to apoptosis. In other words, a paradoxical deleterious response can occur (Horváth et al. 2008, Pittet et al. 2002, Gelain et al. 2011, Heiserman et al. 2015).

Heat shock proteins play a crucial role in embryofetal development. They are involved in every stage of the reproductive process, from formation of the male and female gametes to fertilisation and post-fertilisation 
development. Heat shock protein production is enhanced during in vitro embryo culture and they are among the first proteins produced during mammalian embryo growth. Furthermore, presence or absence of heat shock proteins influences various aspects of reproduction in many species. Various studies have shown that in mice, the $68-70-\mathrm{kDa}$ heat shock proteins appear early in development and are primary products of the zygote (Saito et al. 2013, Morange et al. 1984).

Heat shock protein 70 is present at the blastocyst stage during differentiation of the embryonic internal cellular mass (Wittig et al. 1983). The expression of heat shock proteins appears to be a vital component of the preimplantation embryo. In mice and bovine blastocysts cultured in vitro, introduction of antibodies to the heat shock protein 60 and heat shock protein 70 , as well as anti-heat shock protein 60 and anti-heat shock protein 70 , respectively, significantly inhibits further embryo development (Neuer et al. 1998, Matwee et al. 2001). Role of heat shock protein 60 has been described as being similar to the role heat shock protein 70 . Human antiheat shock protein 60 and human anti-heat shock protein 70 have been detected in peripheral circulation of healthy non-pregnant individuals, as well as in pregnant women as a natural phenomenon (Ziegert et al. 2009).

\section{CAESAREAN SECTION, HEAT SHOCK PROTEINS AND POTENTIAL LINK TO POSTPARTAL DEPRESSION}

Stress response to surgery is modulated by several factors, including magnitude of the injury, type of procedure (e.g. laparoscopy vs laparotomy) and type of anaesthesia. One study showed that in the clinical setting of a low stress laparoscopic surgery, the changes associated with sevoflurane suggest a more favourable metabolic and immune response when compared to isoflurane. In addition, the type of volatile anaesthetic used significantly affected the stress response (Marana et al. 2003). One meta-analysis involving total of 28 studies with total of 532630 participants suggests that caesarean section, as well as the emergent caesarean section, both increase the risk of developing postpartal depression. The authors concluded that adverse physiological outcomes during pregnancy, such as infection, postpartum hemorrhage, uterine rupture, chronic pelvic pain and gastrointestinal dysfunction might enhance surgical trauma and stress during caesarean section, which might increase the risk of postpartal depression (Xu et al. 2017).

It is obvious that heat shock proteins play a certain role in development of psychiatric disorders. However, the exact mechanisms of heat shock protein actions and subsequent effects on psychic status, as well as the potential role of heat shock proteins in etiology of mental disorders are still unclear. In the context of the issue mentioned above, it is also unclear what is the exact role of heat shock proteins in development of postpartal depression.

\section{CONCLUSIONS}

There is a growing incidence of delivery by caesarean section in developed countries which adds to the risk of developing postpartal depression. Heat shock proteins play a role in developing major depressive symptoms. In the context of a higher risk of developing postpartal depression after caesarean section, it is to conclude that heat shock proteins could have a potential role in developing depressive symptoms after caesarean section because they do exert an effect on central nervous system during surgical systemic stress response. It is to highlight the need for a randomised control trial which would enable a more appropriate answer on the issue of involvement of heat shock proteins in development of postpartal depression after caesarean section.

\section{Acknowledgements: None.}

\section{Conflict of interest: None to declare.}

\section{Contribution of individual authors:}

Krunoslav Šporčić \& Slobodan Mihaljević: design of the study, literature searches and analyses, interpretation of data, manuscript writing, approval of the final version

Marko Ćaćić, Krešimir Reiner \& Matko Pavlović: literature searches and analyses, manuscript writing, approval of the final version

\section{References}

1. Barber EL, Lundsberg L, Belanger K, Pettker CM, Funai EF, Illuzzi JL: Contributing Indications to the Rising Cesarean Delivery Rate. Obstet Gynecol 2011; 118:29-38

2. Beilin B, Bessler H, Mayburd E, Smirnov G, Dekel A, Yardeni I, et al: Effects of preemptive analgesia on pain and cytokine production in the postoperative period. Anesthesiology 2003; 98:151-5

3. Bruemmer-Smith S, Stüber F, Schroeder S: Protective functions of intracellular heat-shock protein (HSP) 70expression in patients with severe sepsis. Intensive Care Med 2001; 27:1835-41

4. Gelain DP, de Bittencourt Pasquali MA, M Comim C, et al: Serum heat shock protein 70 levels, oxidant status, and mortality in sepsis. Shock 2011; 35:466-470

5. Guisasola MC, Ortiz A, Chana F, Alonso B, Vaquero J: Early inflammatory response in polytraumatized patients: Cytokines and heat shock proteins. A pilot study. Orthop Traumatol Surg Res 2015; 101: 607-11

6. Hamberger B, Jarnberg PO: Plasma catecholamines during surgical stress. Diferences betwen neurolept and enfluran anaesthesia. Acta Anestesiol Scand 1983; 27:307-10

7. Hashikawa N, Utaka Y, Ogawa T, Tanoue R, Morita Y, Yamamoto S, Yamaguchi S, Kayano M, Zamami $Y$, Hashikawa-Hobara N: HSP105 prevents depression-like behavior by increasing hippocampal brain-derived neurotrophic factor levels in mice. Sci Adv 2017;31:3 
8. Heiserman JP, Chen L, Kim BS, Tran AL, Siebenborn N, Knowlton AA: TLR4 mutation and HSP60-induced cell death in adult mouse cardiac myocytes. Cell Stress Chaperones 2015; 20:527-535

9. Horváth I, Multhoff G, Sonnleitner A, Vigh L: Membraneassociated stress proteins: more than simply chaperones. Biochim Biophys Acta 2008; 1778:1653-1664

10. Kampinga HH, Hageman J, Vos MJ, Kubota H, Tanguay RM, Bruford EA, Cheetham ME, Chen B, Hightower LE: Guidelines for the nomenclature of the human heat shock proteins. Cell Stress Chaperones 2004; 14:105-111

11. Kelbel I, Weis M: Anaesthetics and immune function. Curr Opin Anaesthesiol 2001; 14: 685-91

12. Lanes A, Kuk JL, Tamim H: Prevalence and characteristics of postpartum depression symptomatology among Canadian women: a cross-sectional study. BMC Public Health 2011 May 11. doi:10.1186/1471-2458-11-302. [Epub ahead of print]

13. Lim GY, Tam WW, Lu Y, Ho CS, Zhang MW, Ho RC: Prevalence of Depression in the Community from 30 Countries between 1994 and 2014. Sci Rep 2018; 8:2861

14. Liston WA: Rising caesarean section rates: can evolution and ecology explain some of the difficulties of modern childbirth? J R Soc Med 2003; 96:559-561

15. Liu T, Daniels CK, Cao S: Comprehensive review on the HSC70 functions, interactions with related molecules and involvement in clinical dis- eases and therapeutic potential. Pharmacol Ther 2012; 136:354-374

16. Macario AJ, Conway de Macario E: Molecular chaperones: multiple functions, pathologies, and potential applications. Front Biosci 2007; 2588-2600

17. Malatinsky J, Vigas M, Jurcovicova I, Jezova D, Garayova $S$, Miniarikova M: The patterns of endocrine reponse to surgical stress during different types of anaesthesia and surgery in man. Acta Analg Belg 1986; 37:23-31

18. Marana E, Giusepina AM, Meo F, Parpaglioni R, Galeone M, Maussier ML, Marana R: Sevofluran improves the neuroendocrine stress response during laparoscopic pelvic surgery. Cana J Anesth 2003; 50:348-354

19. Matwee C, Kamaruddin M, Betts DH, Basrur PK, King WA: The effects of antibodies to heat shock protein 70 in fertilization and embryo development. Mol Hum Reprod 2001; 7:829-37

20. Mehlen P, Schulze-Osthoff K, Arrigo AP: Small stress proteins as novel regulators of apoptosis heat shock protein 27 blocks Fas/APO-1-and staurosporine-induced cell death. J Biol Chem 1996; 271:16510-16514

21. Mokart D, Merlin M, Sannini A, Brun JP, Delpero JR, Houvenaeghel $G$, et al: Procalcitonin, interleukin 6 and systemic inflammatory response syndrome (SIRS): early markers of postoperative sepsis after major surgery. British journal of anaesthesia 2005; 94:767-73

22. Morange M, Diu A, Bensaude O, Babinet C: Altered expression of heat shock proteins in embryonal carcinoma and mouse early embryonic cells. Mol Cell Biol 1984; 4:730-5

\section{Correspondence:}

Kresimir Reiner, $M D$

Department of Anesthesiology and Intensive Care Medicine,

Clinic for Obstetrics and Gynecology, University Clinical Hospital Centre Zagreb

Kišpatićeva 12, 10000 Zagreb, Croatia

E-mail:kreso.reiner@gmail.com
23. Neuer A, Mele C, Liu HC, Rosenwaks Z, Witkin SS: Monoclonal antibodies to mammalian heat shock proteins impair mouse embryo development in vitro. Hum Reprod 1998; 13:987-90

24. Pae CU, Mandelli L, Serretti A, Patkar AA, Kim JJ, Lee CU, Lee SJ, Lee C, De Ronchi D, Paik IH: Heat-shock protein-70 genes and response to antidepressants in major depression. Prog Neuropsychopharmacol Biol Psychiatry. 2007: 31:1006-11

25. Pandey P, Saleh A, Nakazawa A, et al: Negative regulation of cyto- chrome c-mediated oligomerization of Apaf-1 and activation of pro- caspase-9 by heat shock protein 90. EMBO J 2000; 19:4310-4322

26. Pasquali MA, Harlow BL, Soares CN, Otto MW, Cohen LS, Minuzzi L, Gelain DP, Moreira JCF, Frey BN: A longitudinal study of neurotrophic, oxidative, and inflammatory markers in first-onset depression in midlife women. Eur Arch Psychiatry Clin Neurosci 2017 May 26. doi: 10.1007/s00406-017-0812-z. [Epub ahead of print]

27. Pittet JF, Lee H, Morabito D, Howard MB, Welch WJ, Mackersie RC: Serum levels of Hsp 72 measured early after trauma correlate with survival. J Trauma 2002; 52:611-617

28. Robert J: Evolution of heat shock protein and immunity. Dev Comp Immunol 2003; 27:449-464

29. Sacredote P, Bianchi M, Gaspani L, et al: The effect of tramadol and morphine on immune response and pain after surgery in cancer patients. Anesth Analg 2000; 90:1411-4

30. Saito FH, Damasceno DC, Dallaqua B, Linhares IM, Rudge $M V C$, et al: Heat shock protein production and immunity and altered fetal development in diabetic pregnant rats. Cell Stress Chaperones 2013; 18:25-33

31. Schmitt E, Gehrmann M, Brunet M, Multhoff G, Garrido C: Intracellular and extracellular functions of heat shock proteins: repercussions in cancer therapy. J Leukoc Biol 2007; 81:15-27

32. Türkan H, Ahmet A, Sayal A, Eken A, Akay K. Karahalil B: Oxidative and antioxidative effects of desfluran and sevoflurane on rat tissue in vivo. Arh Hig Rada Toksikol 2011; 62:113-119

33. Vlachos II, Barbatis C, Tsopanomichalou M, Abou-Assabeh L, Goumas K, Ginieri-Coccossis M, Economou M, Papadimitriou GN, Patsouris E, Nicolopoulou-Stamati P: Correlation between depression, anxiety, and polymorphonuclear cells' resilience in ulcerative colitis: the mediating role of heat shock protein 70. BMC Gastroenterol 2014; 17:14-77

34. Wittig S, Hensse S, Keitel C, Elsner C, Wittig B: Heat shock gene expression is regulated during teratocarcinoma cell differentiation and early embryonic development. Dev Biol 1983; 96:507-14

35. Xu H, Ding Y, Ma Y, Xin X, Zhang D: Cesarean section and risk of postpartum depression: A meta-analysis. $J$ Psychosom Res 2017; 97:118-126

36. Ziegert M, Witkin S, Sziller I, Alexander H, Brylla E, Härtig W: Heat Shock Proteins and Heat Shock Protein-Antibody Complexes $i$ Placental Tissues. Infection Disease in Obstetrics and Gynecology 1999; 7:180-185 